\title{
A Não-globalização Tecnológica da Indústria Brasileira de Polímeros Medida por meio de Patentes
}

\author{
Carlos A. Hemais \\ Elizabeth Omar Ribeiro da Rosa \\ Henrique Machado Barros
}

\begin{abstract}
RESUMO
É discutido o processo de globalização tecnológica, tomando-se por base o que vem ocorrendo com a indústria brasileira de polímeros. A metodologia adotada abrangeu o desenvolvimento de uma base de dados que contém todos os depósitos de patentes feitos no Brasil de 1985 a 1995, bem como entrevistas com executivos de empresas dessa indústria, ligados à área de tecnologia. A análise da base de dados revela que empresas multinacionais patenteiam seus inventos regularmente como extensão de suas atividades de P\&D. Por outro lado, os depósitos feitos por residentes se apresentam de forma aleatória, evidenciando um comportamento eventual e a falta de interesse pela proteção legal dos resultados das pesquisas. Como principal conclusão, a pesquisa sugere que não existe o processo de globalização tecnológica nessa indústria.
\end{abstract}

Palavras-chaves: globalização tecnológica; indústria brasileira de polímeros; patentes; empresas multinacionais.

\begin{abstract}
This paper discusses the process of technological globalization, with particular attention to the case of the Brazilian polymer industry. The instruments used in the study were a data base built with all the patent applications made in Brazil between 1985 and 1995 and interviews with executives who work in the area of technology in firms of the polymer industry. The analysis of the data base revealed that multinational firms patent their inventions regularly as an extension of their R\&D activities. On the other hand, the depots by Brazilian applicants are made in a random manner that shows signs of sporadic behavior and a lack of interest in legal protection for the results of the research. The main conclusion of this study suggests that there is no process of technological globalization in this industry.
\end{abstract}

Key words: technological globalization; Brazilian polymer industry; patents; multinational companies. 


\section{INTRODUÇĀO}

Ao longo das duas últimas décadas, tem havido gradativo aumento na interrelação e interdependência econômica das nações, com o crescimento do fenômeno da globalização dos mercados. Paralelamente a essa nova realidade, o governo brasileiro, desde 1990, vem adotando uma política que busca afastar a intervenção governamental do mercado, abrindo-o ao comércio exterior, e criando nova ordem econômica no país.

A abertura do mercado brasileiro às importações, aliada ao processo de privatização, fez com que o perfil de certos setores da indústria mudasse radicalmente, tal como o que veio a ocorrer com a indústria brasileira de polímeros. As empresas, que tinham mercado interno protegido, subvenções e facilidades de exportação de seus excedentes, passaram a ter de lidar, em sua própria casa, com a agressiva concorrência de fabricantes estrangeiros, que começaram a colocar seus produtos no país por preços atraentes e, muitas vezes, com conteúdo tecnológico mais avançado.

O processo de globalização está sendo sentido, particularmente, pelo setor industrial de polímeros (plásticos, borrachas, fibras, adesivos, tintas e vernizes). A indústria de polímeros é o segmento da indústria química que mais cresce no mundo. Entre 1980 e 1990, a produção mundial de plásticos aumentou 62\%, uma vez que esse material foi progressivamente substituindo outros materiais. Em 1992, a produção de plástico alcançou 102 milhões $\mathrm{m}^{3} / \mathrm{ano}$, enquanto a do aço foi de 50 milhões $\mathrm{m}^{3} /$ ano. A produção de plástico deverá aumentar 10 vezes antes que o mercado global possa ser considerado saturado (Utracki, 1995).

Atualmente a indústria do plástico é responsável no Brasil por $2 \%$ do Produto Interno Bruto (PIB) do país, gera um faturamento anual da ordem de US\$5 bilhões, emprega diretamente quase 200 mil pessoas e responde pelo pagamento de US $\$ 1,5$ bilhão de impostos. O mercado brasileiro é considerado área de oportunidades pelo fato de o país possuir excelente base populacional, que garante demanda constante e porque o consumo per capita é ainda muito baixo, revelando grande potencial futuro em nosso país (Desenvolvimento do Mercado de Termoplásticos, 1995; Perrone, 1996).

É sabido que as empresas pertencentes à indústria de polímeros são dependentes de constantes inovações tecnológicas para se manterem no mercado, uma vez que novos padrões de competitividade se baseiam em intensas atividades de Pesquisa e Desenvolvimento (P\&D); entretanto essa indústria, que se vem desenvolvendo 
no Brasil de forma satisfatória, no que se refere à produção e à transformação dos materiais, pouco tem feito em relação à $\mathrm{P} \& \mathrm{D}$, apesar de toda a sua importância. Por outro lado, as empresas multinacionais vêm investindo, em seus países de origem, milhões de dólares em busca de novas tecnologias, que são patenteadas em várias partes do mundo. Isto afeta todo o processo de concorrência e cria novas oportunidades de mercado (Coronado, 1997).

O presente trabalho examina a existência do processo de globalização tecnológica na indústria brasileira de polímeros. Foi escolhido como ponto de partida para tal exame o número de depósitos de patentes feitos no país no período de 1985 a 1995, uma vez que as patentes são consideradas, juntamente com $P \& D$, os principais indicadores tecnológicos de um país (Jacobsson, Oskarsson e Phipson, 1996). Para complementar as informações coletadas, foram feitas entrevistas com executivos ligados à tecnologia na indústria examinada.

\section{Globalização Tecnológica e Transferência de Tecnologia}

O processo de globalização tecnológica pode possuir, de acordo com Archibugi e Michie (1995), três dimensões distintas: a exploração global de tecnologia, a colaboração tecnológica global e a geração global de tecnologia.

Dessa forma, o intenso fluxo de informações promovido por tais dimensões confere a existência de um fenômeno de transferência tecnológica, compartilhado neste trabalho com a definição de Chesnais (1992, p. 271), de que "a transferência de tecnologia implica a transferência para o recipiente não só do conhecimento técnico necessário para produzir os produtos, mas também da capacidade de dominar conceitualmente, de desenvolver e, depois, produzir de forma autônoma a tecnologia existente atrás desses produtos". As razões para ocorrer transferências de tecnologia são retratadas por Hemais (1997) como: (1) o uso recíproco da tecnologia; (2) a necessidade de rápida padronização de uma determinada tecnologia; (3) a disponibilidade de conhecimento não-estratégico armazenado; (4) a maximização do uso de uma tecnologia; (5) a obtenção de margem comercial sobre os competidores; (6) a existência de barreiras para se ter acesso ao mercado; (7) a transferência de uma tecnologia commodity antes dos competidores; e (8) a grande oportunidade de mercado no país hospedeiro. Essas razões estão mais relacionadas à exploração global da tecnologia.

A atividade de geração global de tecnologia também é retratada na literatura, onde foi observado que a prática de investimentos diretos nas atividades de $\mathrm{P} \& \mathrm{D}$ conheceu um crescimento que reflete os esforços empregados pelas empresas para 
reforçarem suas capacidades científicas e tecnológicas e para gerarem novos ativos tecnológicos (Ronstadt, 1984; Casson, 1991; Kummerle, 1997). Por sua vez, Dunning (1994) identificou outras razões para as empresas investirem em P\&D no exterior: (1) o interesse em melhorias ou adaptações de insumos, produtos e/ou processos; (2) a presença, no país hospedeiro, de insumos sem mobilidade (ex.: plantação, minério); (3) a perspectiva de racionalização da pesquisa (equivalente à redução de custos de produção); e (4) a manutenção de uma proximidade com as atividades de pesquisa no exterior. Florida (1997) complementa, observando que os laboratórios de $\mathrm{P} \& \mathrm{D}$, situados em países distintos daquele onde a empresa se originou, possuem enfoque tanto para o mercado como para a tecnologia e relacionou em seu trabalho as atividades mais importantes: (1) desenvolvimento de idéias para novos produtos; (2) obtenção de informações sobre desenvolvimentos técnicos e científicos do país hospedeiro; (3) contratação de talentos técnicos e científicos; (4) adequação dos produtos ao mercado do país hospedeiro; (5) estabelecimento de relações com a comunidade técnico-científica local; trabalho com as instalações de produção da matriz; e (6) desenvolvimento de novas ciência e tecnologia.

Além disso, Chesnais (1988) observa que a tendência para intensificar o processo de globalização tecnológica se deve, além do ambiente econômico mundial, a dois principais conjuntos de fatores. $O$ primeiro deles seria o estágio alcançado pelo processo de internacionalização, que traz consigo a denominada competição global, a qual, nas indústrias intensivas em P\&D e naquelas cujas economias de escala são decisivas, tomou a seguinte forma: (1) ocorre entre pequeno número de grandes empresas; (2) está estabelecida em nível mundial; e (3) se processa por meio de diversos meios de acesso às tecnologias e aos mercados. O outro conjunto de fatores está relacionado ao fato de que o acesso à tecnologia e à ciência, buscado anteriormente como forma de obtenção de vantagens competitivas, atualmente tornou-se uma necessidade.

Embora a tendência supracitada esteja ocorrendo eventualmente, Patel e Pavitt (1992) observaram que $85 \%$ das atividades de P\&D de empresas alemãs, francesas, italianas, japonesas e norte-americanas são desenvolvidas no seu respectivo país de origem. Além disso, muito pouco foi desenvolvido fora dos países da triad (Estados Unidos, Japão e Europa Ocidental).

Perrino e Tipping (1989) argumentam que enquanto os mercados estão assumindo uma natureza global, o desenvolvimento tecnológico não o está. Isso porque as novas tecnologias e os talentos necessários para desenvolvê-las continuam pertencendo a núcleos específicos. Tal comportamento coloca os países em desenvolvimento à margem do processo de inovação. Na mesma linha de pensamento, Freeman (1995) expôs que o processo de globalização exige padronização global, 
mas que esta não abrange todas as áreas, tendo em vista que inúmeros produtos aglutinam em torno de si determinadas características (preferências, regulamentações, clima, aspectos culturais etc) que não podem ser ignorados. Desse modo, as atividades de $\mathrm{P} \& \mathrm{D}$ provenientes da internacionalização foram conduzidas à adaptação e à modificação de produtos para atender às especificações locais; porém aquele autor sugere que o referencial de propriedade e controle das atividades de P\&D continua sendo nacional, isto é, do país de origem da empresa. Nesse sentido, o autor argumenta que há possibilidade de existência de uma triadização, mas não de um fenômeno de globalização tecnológica responsável pela geração global de tecnologia.

A literatura sobre globalização tecnológica referente a países em desenvolvimento é limitada, ainda mais, quando o Brasil é o foco das atenções. Por causa disso, merecem atenção os estudos de Maldonado (1996) e Rosa (1998), que ratificam, em parte, a tese de não-globalização tecnológica, uma vez que os autores não observaram a presença de empresas que gerem tecnologia no país por meio do exercício de atividades de pesquisa e desenvolvimento.

\section{Papel da Propriedade Industrial na Economia de Mercado}

Em seu clássico trabalho sobre economia da firma, Penrose (1980) considera a patente uma barreira aos inventores locais porque, em geral, o objetivo do detentor da patente é retardar o desenvolvimento tecnológico de seus concorrentes. Penrose (1980) entende que o benefício auferido pela patente é exclusivo do detentor e exportador do objeto da patente. E que o monopólio é mais do interesse dos grandes grupos industriais, estabelecidos nos países industrializados, porque têm ampla infraestrutura industrial e também alta taxa de inovação. Para países não-industrializados e aqueles em estágios iniciais de industrialização, os ganhos são nulos.

Pavitt (1988) reconhece ser a capacidade para as rápidas e contínuas mudanças tecnológicas uma das características do sistema capitalista atual. Afirma, ainda, que tanto as empresas multinacionais como o sistema de patentes são componentes essenciais deste capitalismo dinâmico. As multinacionais são definidas por Pavitt (1988) como a principal fonte das mudanças tecnológicas e o sistema de patentes como parte dos incentivos.

Diante da velocidade com que têm ocorrido as mudanças nas últimas duas décadas, as empresas viram-se diante de novos desafios e tiveram de buscar meios para se tornarem mais competitivas, cada vez mais apostando na inovação tecnológica e em P\&D como ponto de vantagens diferenciais e fator de 
competitividade, crescimento econômico e de geração de empregos. Por outro lado, é necessário garantir o monopólio nos setores de atividades que sejam de extrema importância para o crescimento contínuo e para a apropriação dos resultados advindos da inovação, o que, muitas vezes, não é conseguido no mercado nacional dessas empresas. Assim, para obterem economia de escala na produção e diluir os custos dos altos investimentos em $\mathrm{P} \& \mathrm{D}$, as empresas são obrigadas a buscar mercados internacionais. Dessa forma, a competição internacional se transformou em uma das principais barreiras que importa vencer (Barros, Pastorini e Hemais, 1997).

De acordo com Bertin e Wyatt (1988), as estratégias para a proteção internacional da tecnologia se transformou numa área de extrema importância para as empresas multinacionais. O que se observou como resultado desta nova consciência foi o aumento da internacionalização da economia e do comércio entre nações e do comércio exterior. Observou-se, ainda, a intensificação e a generalização da participação e controle desses grupos, em todos os setores da economia, como o resultado da conjugação de fatores favoráveis consubstanciados no elenco seguinte:

- a expansão dos mercados internacionais gera a necessidade de meios internacionais de controle e proteção industrial, como os acordos de comércio exterior, que também incluem matéria pertinente à propriedade industrial;

- a existência de grande número de métodos para a proteção das vantagens tecnológicas (patentes, segredo, lead time, esforços de vendas);

- a existência de corporações industriais espalhadas pelo mundo e que possuem estratégias globais e recursos consideráveis.

Assiste-se, assim, a partir da década de 80, à transição dos processos tecnológicos clássicos para um novo momento, em que surge a necessidade de altos investimentos em $\mathrm{P} \& \mathrm{D}$, a ampliação de mercados a título de acelerar a taxa de retorno e redução das incertezas e riscos associados às novas invenções. A tecnologia passa a ser elemento fundamental, que se junta à mão-de-obra, ao capital e às matériasprimas para explicar novas formas de competitividade e conquistas de mercado no novo ambiente macroeconômico (Tachinardi, 1993).

A inovação e P\&D tem hoje papel preponderante no aumento da competitividade. As vantagens competitivas e a especialização são determinadas no mundo contemporâneo pela capacidade do uso do conhecimento científico e da tecnologia, requisitos essenciais para a inserção dos países no sistema internacional. Para manter essa competitividade em bens de alta tecnologia, os inovadores viram-se diante da necessidade de se apropriar financeiramente do conhecimento científico e tecnológico de suas inovações, mediante a proteção oferecida pela patente. 


\section{Metodologia}

Para se examinar o processo de globalização tecnológica da indústria brasileira de polímeros, adotou-se como metodologia a construção de uma base de dados, com informações sobre depósitos de patentes no Brasil, de 1985 a 1995. Essas informações foram complementadas com entrevistas pessoais havidas com 5 executivos da indústria, ligados à área tecnológica.

A partir de fichas técnicas obtidas por especial concessão da Diretoria de Patentes do Instituto Nacional de Propriedade Industrial (DIRPA), foi montada uma base de dados. Essa base reúne informações sobre todos os depósitos de patentes em polímeros feitos no Brasil, no período de 1985 a 1995, dentro da Seção C, Classe C08: trata-se de compostos macromoleculares orgânicos, da sua preparação ou do seu processamento químico e as composições baseadas neles. $\mathrm{O}$ ano inicial de 1985 foi escolhido devido ao fato de que, antes disso, os dados não estavam disponíveis no INPI de forma imediata. Do mesmo modo, após 1995, os pedidos de patentes ainda se encontravam em estado de sigilo por ocasião da montagem da base de dados. Torna-se necessário esclarecer que um pedido de patente depositado, segundo as normas que emanam da Convenção da União de Paris, leva 18 meses em sigilo, contados da data de depósito no Brasil ou da prioridade mais antiga, até sua publicação. Por exemplo, um pedido depositado em julho de 1996, somente foi publicado em janeiro de 1998, quando os trabalhos da presente pesquisa já se haviam encerrado. Por outro lado, um pedido de patente depositado segundo às disposições do PCT levará pelo menos 20 meses para sua entrada na fase nacional, ou seja, a designação do Brasil como país selecionado para depósito.

Adotou-se como parâmetro de investigação o depósito de pedidos de patentes (e não as patentes concedidas no Brasil), uma vez que a ação do depósito de um pedido de patentes denota a vontade do inventor (pessoa física ou jurídica) em fazê-lo. Essa ação pode ser entendida como política interna de propriedade industrial existente na empresa. Por outro lado, a concessão de patente não depende exclusivamente da vontade do depositante: depende de fatores alheios à própria empresa, como por exemplo, a lei de propriedade industrial que regulamenta a sua concessão.

A base de dados construída contém informações sobre o nome da empresa, país de origem, número do depósito no INPI, que indica o ano em que foi feito o depósito, a primeira classificação internacional e a classificação do depositante.

A pesquisa foi complementada por meio de entrevistas com profissionais 
especializados em algumas empresas produtoras de polímeros. Utilizou-se amostra de conveniência para a escolha desses profissionais. Foram realizadas 5 entrevistas com profissionais de $\mathrm{P} \& \mathrm{D}$ de empresas ligadas aos pólos petroquímicos brasileiros.

As empresas entrevistadas estão em operação desde a principal fase da implantação da indústria de polímeros no país, sendo que 3 pertencem ao setor de plásticos e 2 ao setor de borracha.

Dessas empresas, uma sempre teve capital privado e quatro faziam parte do Sistema Petroquisa e foram privatizadas na década de 90; duas passaram, recentemente, a ser controladas majoritariamente por empresas multinacionais e uma delas transferiu parte de suas linhas de produção para uma multinacional. Embora fosse utilizada amostra de conveniência, foi possível pesquisar algumas das principais empresas, instaladas no país, que possuem suas unidades fabris localizadas nos maiores complexos industriais petroquímicos. A Tabela 1 apresenta, em resumo, os dados das empresas estudadas.

Tabela 1: Empresas de Polímeros Constantes da Amostra Estudada

\begin{tabular}{|c|c|c|c|c|}
\hline Empresa & $\begin{array}{l}\text { Faturamento } \\
\text { US\$ milhões }\end{array}$ & \% para P\&D & Controle & $\begin{array}{c}\text { Capacidade } \\
\text { mil ton/ano }\end{array}$ \\
\hline A & 300 & 1,00 & nacional & n.d. \\
\hline B & 300 & 0,70 & estrangeiro & 430 \\
\hline C & 60 & 0,50 & estrangeiro & 41 \\
\hline D & 300 & 0,30 & nacional & 330 \\
\hline E & 150 & 0,70 & nacional & 140 \\
\hline
\end{tabular}

\section{Descrição e Análise dos Resultados}

As tabelas e gráficos a seguir são baseados no número total de pedidos de patentes de invenção depositados no Brasil na Classe C08, no período de 1985 a 1995. Esse período foi escolhido de acordo com a metodologia adotada pela pesquisa, que somente considerou os pedidos de invenção depositados e publicados. Nesse período de 11 anos, foram feitos 4.554 pedidos de patentes válidos, que vieram a se constituir no universo estudado.

\section{Depósito de Patentes}

O Gráfico 1 apresenta o número de depósitos de pedidos de invenção efetuados no Brasil, na Seção C08, quais sejam, polissacarídeos, borrachas, polímeros olefínicos, polímeros de condensação, macromoléculas naturais, processos poliméricos, aditivos e composições poliméricas. 


\section{Gráfico 1: Depósitos Totais de Pedidos de Patentes no Brasil Seção C08 - Polímeros (1985-1995)}

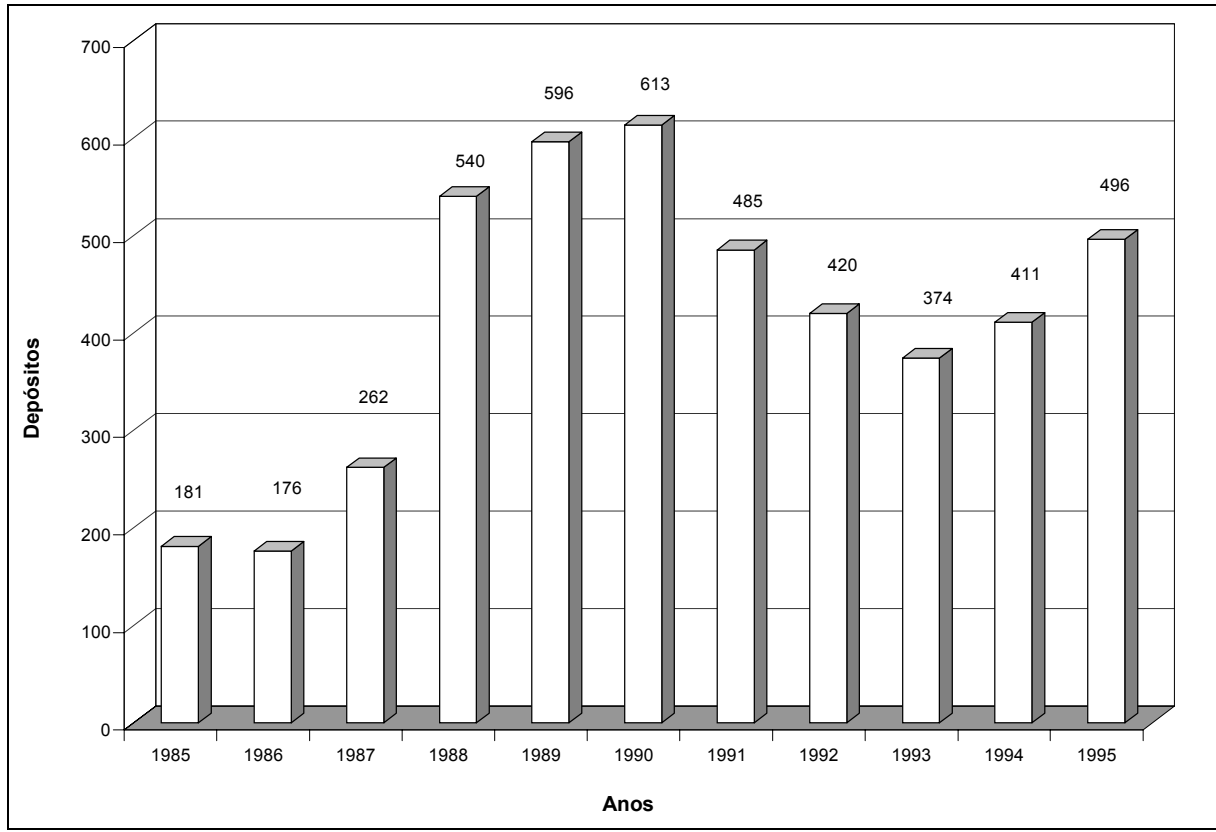

Observa-se baixo nível de patenteamento no biênio 1985-1986, que talvez possa ser explicado, em nível nacional, pela recessão econômica pela qual passava o país, e que obrigou as empresas a fazer cortes de despesas em todos os setores. Isto foi particularmente verdadeiro para os setores de $\mathrm{P} \& \mathrm{D}$, que passaram a funcionar de forma seletiva, escolhendo com mais rigor a tecnologia que queriam patentear.

Em termos internacionais, a visão que as empresas talvez tivessem da economia brasileira, que passava por um período de grandes instabilidades e por diversos planos radicais de ajuste econômico, certamente afetou o índice de depósito de patentes, uma vez que os riscos aparentes eram grandes e a atratividade do mercado não os compensava. Isto poderia ter feito com que as empresas não se sentissem estimuladas a empreender despesas com o custo de depósito e manutenção de muitas patentes, que envolviam pequenos aperfeiçoamentos. Elas podem ter optado pela proteção patentária somente da porção fundamental de sua tecnologia no país.

O final da década de 80 apresenta panorama diferente, com aumento acentuado do número de depósitos. O fato talvez possa ser explicado pelo proces- 
so de globalização industrial, que já se tornava forte e exercia grande influência sobre as estratégias de P\&D das empresas. Estas se viram obrigadas a acelerar o desenvolvimento de novos produtos, catalisadores, processos, composições e compósitos, o que também se refletiu no Brasil, país reconhecidamente grande receptor de tecnologia externa e possuidor de um mercado competitivo e potencial para os plásticos commodities e de engenharia. Tudo isso, somado à necessidade de proteção jurídica e à capacidade de realização de engenharia reversa de nossas empresas, pode ter contribuído para o aumento do número de depósitos.

A queda acentuada no início da década de 90 se deve ao novo processo de instabilidade econômica no país, o que veio a ser controlado, em 1994, com o início do Plano Real. A confiança das empresas no plano se fez sentir quase que imediatamente, com o aumento do número de depósitos, uma vez que o mercado voltou a ser atrativo. Ao mesmo tempo, em 1996, o Brasil aprovou, após longo período de discussões, a nova lei de propriedade industrial, definindo uma realidade nova para o setor. Por outro lado, com o crescimento de quase $20 \%$ do mercado de commodities no país, é razoável se esperar que haja aumento constante nos depósitos dos inventores não-residentes, ainda por bom período.

\section{Países Depositantes}

O levantamento de dados averiguou que 28 países depositaram pedidos de patentes no país; porém somente 10 deles, incluindo o Brasil, depositaram pedidos em percentuais acima de $1 \%$ no período de 11 anos. A Tabela 2, a seguir, apresenta esses países, relacionando-os com o número de pedidos de invenção, no período de 1985 a 1995 , e seus respectivos percentuais.

Observa-se que o país que mais deposita pedidos de patentes de invenção no Brasil são os Estados Unidos, seguidos da Alemanha. O Brasil ocupa a sexta posição entre os depositantes de patentes. Os esforços de $\mathrm{P} \& \mathrm{D}$ realizados pelo país contribuem com apenas $4,3 \%$ do total de pedidos feitos.

Casos como os da Holanda e da Bélgica merecem ser destacados, pois retratam a realidade de países que, em face da escassez de recursos naturais, se transformaram em importantes centros de desenvolvimento tecnológico, apostando sua política desenvolvimentista em explorar com sucesso seus principais recursos disponíveis: mão-de-obra altamente qualificada, estrutura atuante de centros de pesquisa e universidades e custos razoavelmente mais baixos em comparação aos de outros países desenvolvidos. 
Tabela 2: Depósitos de Pedidos de Invenção no Brasil - País de Origem Seção C08 - Polímeros (1985-1995)

\begin{tabular}{|l|c|c|}
\hline \multicolumn{1}{|c|}{ País de Origem } & Número de Pedidos & \% \\
\hline Estados Unidos & 2.356 & 51,7 \\
\hline Alemanha & 514 & 11,3 \\
\hline Holanda & 340 & 7,5 \\
\hline Japão & 254 & 5,6 \\
\hline França & 240 & 5,3 \\
\hline Brasil & $\mathbf{1 9 6}$ & $\mathbf{4 , 3}$ \\
\hline Suíça & 164 & 3,6 \\
\hline Grã-Bretanha & 156 & 3,4 \\
\hline Itália & 143 & 3,1 \\
\hline Bélgica & 65 & 1,4 \\
\hline Outros & 126 & 2,8 \\
\hline TOTAL & $\mathbf{4 . 5 5 4}$ & $\mathbf{1 0 0 , 0}$ \\
\hline
\end{tabular}

A análise da Tabela 2 aponta para a hegemonia americana no que se refere a depósitos de patentes, bem como para o potencial do mercado brasileiro, que desperta interesse da indústria americana e européia.

\section{Origem dos Depósitos de Patentes}

A Tabela 3 apresenta o número de depósitos de pedidos de invenção efetuados no período considerado de 11 anos, segundo a categoria do depositante.

Tabela 3: Depósitos de Pedidos de Invenção no Brasil - Tipos de Depositantes Seção C08 - Polímeros (1985-1995)

\begin{tabular}{|l|c|c|c|c|}
\hline \multirow{2}{*}{ Classificação } & \multicolumn{2}{|c|}{ Residentes } & \multicolumn{2}{c|}{ Não-Residentes } \\
\cline { 2 - 5 } & Quantidade & $\mathbf{\%}$ & Quantidade & \% \\
\hline Empresa nacional & 71 & 1,6 & -- & -- \\
\hline Empresa multinacional & 45 & 1,0 & 4.293 & 94,3 \\
\hline Inventor individual & 68 & 1,5 & 34 & 0,7 \\
\hline $\begin{array}{l}\text { Universidades, centros de pesquisa, } \\
\text { ógãos governamentais etc }\end{array}$ & 12 & 0,2 & 31 & 0,7 \\
\hline \multicolumn{1}{|c|}{ Total } & 196 & 4,3 & 4.358 & 95,7 \\
\hline \multicolumn{2}{|c|}{} & & & \\
\hline
\end{tabular}


Observa-se, mais uma vez, que as empresas multinacionais não-residentes no país são as maiores usuárias do sistema, aparecendo com 4.293 depósitos ao longo de período de 11 anos, representando um percentual de 94,3\%. Inventores não-residentes e universidades estrangeiras são esporádicos e aparecem com percentuais de $0,7 \%$ cada.

As empresas multinacionais residentes no país depositaram 45 pedidos, ou seja, somente $1,0 \%$ desses pedidos, o que demonstra que essas empresas pesquisam muito pouco no Brasil, e que, certamente, todo P\&Dé feito em seus países de origem ou em centros de pesquisa localizados em outro país onde a empresa opere.

As empresas nacionais residentes no país depositaram no período apenas 71 pedidos, representando um percentual de 1,6\%. Esse dado comprova as premissas anteriores de que a empresa nacional desenvolve poucas atividades de $\mathrm{P} \& \mathrm{D}$ ou, se realiza, não têm como objetivo o depósito de pedidos de patentes.

Curioso é que os inventores residentes no país depositaram 68 pedidos no período, representando 1,5\% do total. Esse percentual, quando comparado ao percentual dos pedidos feitos pelas empresas nacionais, surge como valor considerável. Podese atribuir esse fato ao desinteresse das empresas e universidades em depositar os pedidos e o reconhecimento do valor do sistema pelo inventor, conduzindo-o ao depósito em seu próprio nome.

As universidades surgem com apenas 12 pedidos no período, ou seja, $0,2 \%$ do total. Esse dado pode ser considerado alarmante; certamente, a maior parte de P\&D realizada está sendo colocada à disposição do público por meio de trabalhos publicados, e, provavelmente, sendo utilizada sem qualquer ganho para quem investiu em seu desenvolvimento. Situação agravante é encontrada quando essa tecnologia retorna ao país sob a forma de patente, cuja titularidade é estrangeira e que ainda se tem de pagar royalties para utilizá-la.

Os Gráficos 2 e 3 na seqüência apresentam o corte anual dos depósitos de pedidos de invenção, segundo a tecnologia e a origem do depositante, isto é, depositantes residentes e não-residentes no país.

Observa-se no Gráfico 2, que representa o número de depósitos de não-residentes, que as curvas seguem uma tendência regular. Essa tendência demonstra que a produção de tecnologia passível de ser patenteada é atividade rotineira das empresas estrangeiras. Investem-se milhões de dólares regularmente em P\&D e a geração de novas tecnologias é constante. A principal razão que influencia o maior ou menor número de depósitos de patentes deve ser encontrada em fatores macroeconômicos nacionais e internacionais. Assim, se o mercado é atraente e as condições macroeconômicas do país são favoráveis, as empresas se sentem estimuladas a proteger para si parcela desse mercado mediante a patente. Se, porém, 
um quadro de instabilidade econômica se estabelece, isto deve acarretar uma sensível diminuição no número de depósitos, uma vez que o mercado perde grande parte de sua atratividade.

\section{Gráfico 2: Depósitos de Pedidos de Invenção no Brasil - Não-residentes Seção C08 - Polímeros (1985-1995)}

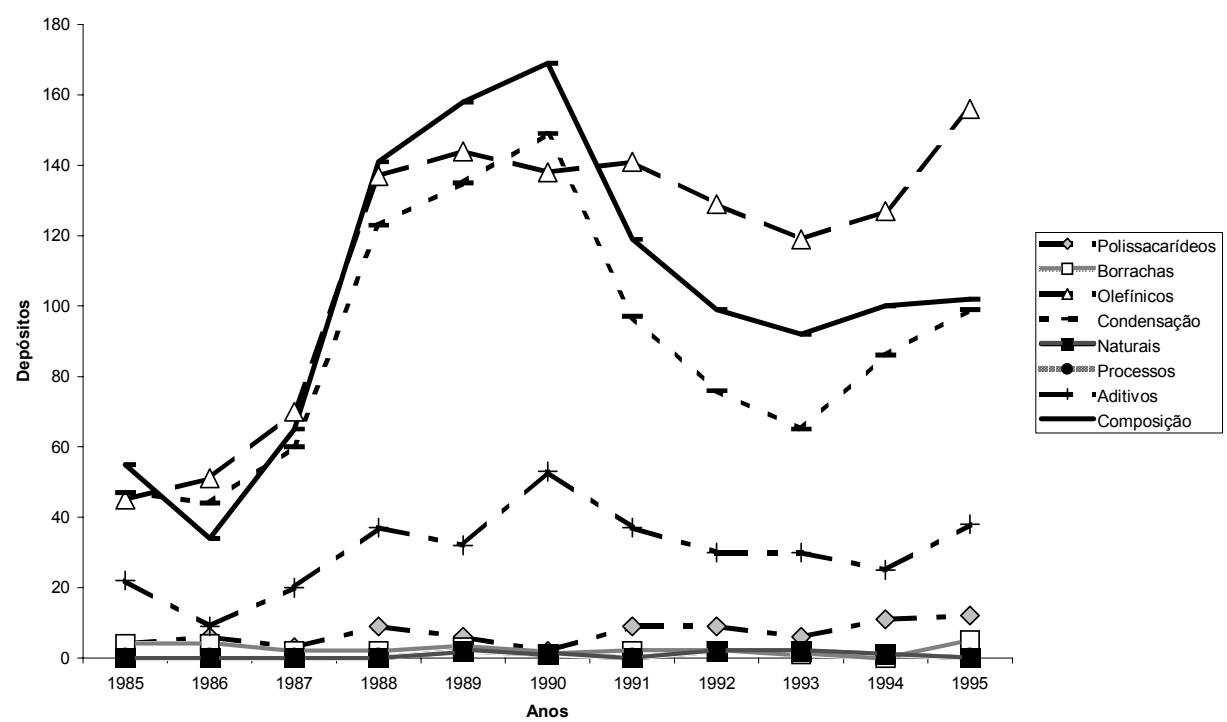

\section{Gráfico 3: Depósitos de Pedidos de Invenção no Brasil - Residentes Seção C08 - Polímeros (1985-1995)}

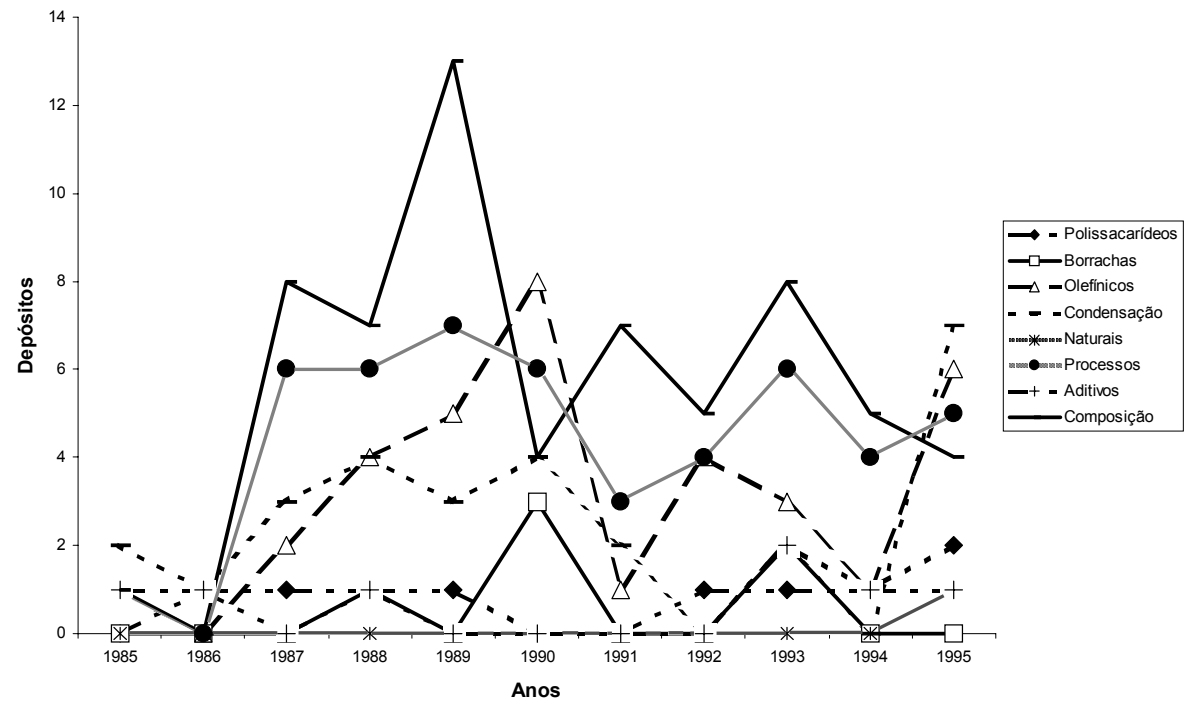


Por outro lado, a observação do comportamento das curvas do Gráfico 3 não revela nenhuma propensão. Os depósitos se apresentam de forma totalmente aleatória e a tendência das curvas é de difícil previsão. Pode-se afirmar que o comportamento do inventor nacional é eventual, não é fruto de atividade regular de pesquisa, as firmas não dão a devida importância ao patenteamento e não deve existir uma atividade de $\mathrm{P} \& \mathrm{D}$ estruturada no país, na área de polímeros, visando a gerar nova tecnologia.

\section{Nível de Patenteamento}

O exame do banco de dados criado especificamente para a presente pesquisa demonstrou que os residentes (empresas brasileiras, subsidiárias brasileiras de multinacionais estrangeiras, bem como inventores individuais, universidades e centros de pesquisa) não cultivam o hábito de depositar patentes na área de polímeros (Seção C08). No período de 11 anos estudado (1985-1995), foram feitos 4.554 pedidos de invenção no Brasil, dos quais somente 196 são de residentes no país, representando $4,3 \%$ do total de depósitos.

Segundo as entrevistas realizadas, as empresas nacionais não depositam pedidos porque não reconhecem o sistema de patentes como uma ferramenta eficiente de estímulo à inovação e ao desenvolvimento tecnológico. Entendem que seu custo é muito alto e que a burocracia o torna moroso. Como resultado, qualquer atividade de $\mathrm{P} \& \mathrm{D}$ existente não está direcionada para a obtenção da proteção legal. As empresas entrevistadas entendem, ainda, que, através do depósito de pedido de patente, pode existir a facilidade da cópia e imitação de seus produtos. Assim, as empresas preferem manter o segredo industrial como estratégia regular.

Outro fator que contribui fortemente para a falta de uma política de propriedade industrial e, conseqüentemente, o baixo nível de patenteamento na indústria nacional é a ausência de atividades regulares de P\&D para o desenvolvimento de novas tecnologias. As empresas examinadas se limitam à pesquisa de adaptação de produtos e processos às necessidades nacionais, ou seja, a pesquisa está unicamente voltada para aperfeiçoamentos incrementais e nunca para invenções de novidade absoluta. Os executivos entrevistados consideram a pesquisa algo de alto custo e risco.

A escala de produção muitas vezes impede as empresas de aplicarem recursos em P\&D. Nesse caso o máximo que elas conseguem fazer é acompanhar a evolução da tecnologia no mundo e aperfeiçoar seus produtos, adaptando-os às exigências do mercado. A cultura estabelecida de aquisição de tecnologia, enraizada na indústria desde sua implantação no Brasil, é fator determinante para se entender por que não é maior o número de depósitos feitos por residentes. 
Por outro lado, a presença constante do detentor de tecnologia no seio das empresas, influenciando na política tecnológica, inibe o desenvolvimento de novos produtos e/ou processos. Na qualidade de acionista, o sócio estrangeiro, detentor de tecnologia, influencia a estratégia tecnológica da empresa e não incentiva a criação de grupos de $\mathrm{P} \& \mathrm{D}$ atuantes, que poderiam ser sérios competidores com seus próprios departamentos de P\&D. Uma vez que o fornecedor de tecnologia possui recursos humanos altamente qualificados, equipamentos de última geração e centros de pesquisa muito bem aparelhados em seus países de origem, a possibilidade de o sócio brasileiro elaborar estratégias tecnológicas calcadas em P\&D autóctone é muito remota. Assim, o número de pedidos de patentes depositados é insignificante.

Se a empresa nacional está ligada a um licenciador estrangeiro através de contratos de fornecimento de tecnologia, este último pode ser maleável e repassar o conhecimento, ou pode ser restritivo, impedindo a engenharia reversa ou obrigando o repasse de todo aperfeiçoamento desenvolvido pelo licenciado. O detentor de tecnologia estrangeiro, principalmente após a desestatização, continua atuando e influenciando nos rumos das empresas do setor. Em sua maioria, os entrevistados consideram o processo de aquisição de tecnologia mais rápido, eficiente e de fácil consolidação, apesar de já conhecer os efeitos de um mercado mundial globalizado, onde a tecnologia é reconhecidamente um bem móvel que se licencia a preços de ouro.

As empresas multinacionais residentes no país não depositam pedidos de patentes nacionais, ou seja, pedidos cuja origem do depósito seja o Brasil. Foi verificado que essas empresas pesquisam em seus países de origem e efetuam os depósitos de pedidos de patentes em diversos países.

\section{Processo de Patenteamento}

A produção de tecnologia passível de ser patenteada é atividade rotineira nas empresas estrangeiras. O orçamento anual dessas empresas, no que se refere a $\mathrm{P} \& \mathrm{D}$, chega a milhões de dólares e a geração de novas tecnologias é constante. Essas empresas tratam o depósito de patentes como rotina profissional, fruto dos resultados das pesquisas realizadas: a proteção do mercado e dos direitos advindos da propriedade industrial são itens prioritários e a conseqüência natural da atividade de pesquisa.

Fatores macroeconômicos nacionais e internacionais influenciam o maior ou menor número de depósitos que fazem. Assim, um bom mercado merece ser protegido; isto é feito regularmente, em especial se as condições macroeconômicas do país são favoráveis. A diminuição de depósitos, por outro lado, pode ser atribuída 
a um quadro de instabilidade econômica, que traz consigo perda de atratividade do mercado.

Em contrapartida, o comportamento do depositante residente é aleatório, e a função inventiva é ocasional. Os dados apresentados parecem refletir uma atividade amadorística e eventual, no que se refere a depósitos de patentes, o que denota que o foco da $\mathrm{P} \& \mathrm{D}$ realizada nas empresas do país não visa, prioritariamente, a gerar nova tecnologia e, conseqüentemente, à obtenção de patentes.

O depósito de pedidos de patentes no Brasil na tecnologia de polímeros é totalmente dominado pelas empresas multinacionais não-residentes no país, uma vez que mais de $95 \%$ dos depósitos efetuados no país procede de pesquisas desenvolvidas em laboratórios estrangeiros.

As empresas nacionais, mesmo depositando pedidos de patentes e tendo as patentes concedidas, continuam utilizando-se da tecnologia contratada. Somente uma das empresas entrevistadas usa a tecnologia desenvolvida e patenteada em sua planta industrial.

Curiosamente, o estudo constatou que o nível de patenteamento de inventores individuais é muito alto, quando comparado ao nível de depósito das empresas nacionais. Esse dado pode ser justificado pela falta de política de propriedade industrial nessas empresas, universidades e centros de pesquisa do país, o que leva o próprio pesquisador a arcar com todos os custos e ônus do depósito de um pedido de patentes que trate de sua invenção, ao invés de deixá-la cair no domínio público.

\section{Dependência Tecnológica}

A pesquisa realizada na base de dados e as entrevistas apontaram para uma grande dependência tecnológica das empresas nacionais. De forma simplista, a aquisição de tecnologia origina altas remessas de royalties para o exterior e não gera o efetivo desenvolvimento tecnológico tão desejado. Alguns gerentes de tecnologia afirmam ser o segredo a melhor forma de proteção, mas o estágio tecnológico da indústria brasileira atual não denota serem as nossas empresas detentoras de tecnologia por meio da manutenção do segredo industrial.

A própria essência do sistema de patentes é a economia, que cada vez mais exige a disseminação do conhecimento para que o desenvolvimento econômico possa acontecer. Hoje, os novos padrões de competitividade fazem com que a economia global se transforme em velocidade cada vez maior. Os produtos comercializados incluem serviços, investimentos e, principalmente, tecnologia. A tecnologia se tornou o elemento fundamental para agregar valor econômico aos produtos. A ênfase passou a ser a produção e consumo de bens e serviços com 
conteúdo tecnológico cada vez maior. Os altos investimentos em P\&D, necessários para as empresas se manterem competitivas, fazem com que a tecnologia seja cada vez mais vista como bem de grande valor econômico, que deve ser comercializada para lhes garantir o retorno certo do investimento.

A indústria de polímeros depende de constantes inovações tecnológicas para se manter no mercado. A realidade encontrada no Brasil, entretanto, faz descortinar um cenário de dependência tecnológica avassalador.

\section{CONCLUSÕES}

Surge de forma clara que a indústria brasileira de polímeros não tem como política interna das empresas o depósito de pedidos de patentes. À primeira vista, poderíamos atribuir tal comportamento à maneira conforme essa indústria se estabeleceu no país. A indústria de capital nacional, em sua maioria, sempre contratou tecnologia; a multinacional sempre desenvolveu sua tecnologia em seu país de origem. Nesse caso, torna-se difícil para a indústria brasileira de polímeros ter seu próprio projeto de pesquisa e desenvolvimento, como também aos órgão governamentais estimular e implantar uma cultura de propriedade industrial.

As empresas não depositam pedidos de patentes, porque não desenvolvem efetivamente $\mathrm{P} \& \mathrm{D}$. Entendem que a pesquisa nas empresas está voltada unicamente para aperfeiçoamentos incrementais, e não para as invenções de novidade de cunho absoluto. Preferem o segredo industrial para o pouco desenvolvimento tecnológico que realizam, mesmo em se tratando de tecnologia de ponta. Entendem, ainda, que o custo do sistema é muito alto para ser mantido e o vêem como um meio de apropriação indevida do conhecimento e imitação dos seus produtos e processos. Não estimulam $\mathrm{P} \& \mathrm{D}$, porque consideram essa atividade de alto custo e risco; preferem a aquisição de tecnologia: a mentalidade de que a compra é mais rápida, mais barata e mais eficiente ainda persiste.

A pesquisa também verificou que o hábito de depositar pedidos de patentes não é cultivado entre as empresas produtoras de polímeros nacionais e multinacionais residentes no país, ao passo que as empresas multinacionais não-residentes no Brasil o fazem como ações cotidianas.

A pesquisa mostrou que executivos, gerentes de P\&D e de tecnologia, muitas vezes, sentem dificuldade em implantar uma política tecnológica e de propriedade industrial nas suas empresas por diversas razões. O baixo nível de patenteamento nesses casos é atribuído principalmente à forma como a indústria petroquímica se instalou no país, onde a maior parte da produção industrial estava apoiada em tecnologia adquirida, 
que era procedente de parceiro ou fornecedor estrangeiro; o atraso é ainda atribuído à influência que o detentor de tecnologia estrangeiro tem na política tecnológica da empresa, que é de vital importância para as estratégias de P\&D.

A influência do detentor de tecnologia é vista sob dois aspectos: quando ele é acionista da empresa com poder de voto, e quando é mero licenciador de tecnologia. A sua presença como acionista é observada como fator inibidor na implantação de uma estratégia tecnológica calcada no desenvolvimento de $\mathrm{P} \& \mathrm{D}$ e, conseqüentemente, de propriedade industrial, uma vez que é ele quem desenvolve tecnologia. Sendo assim, a possibilidade de desenvolvimento tecnológico na empresa instalada em país de terceiro mundo está descartada.

Quando a empresa está ligada a um licenciador por meio de contratos de fornecimento de tecnologia, o repasse do conhecimento depende das bases do acordo. Nos contratos de transferência de tecnologia, em que todo o know-how é repassado, a negociação é mais fácil; entretanto, nos acordos de compra de tecnologia, o repasse do conhecimento pode não ocorrer, como também as cláusulas contratuais podem ser extremamente restritivas, impedindo a engenharia reversa, ou obrigando o repasse de todo o aperfeiçoamento desenvolvido pelo licenciado.

Esse detentor de tecnologia estrangeiro, mesmo após a desestatização, continua atuando e influenciando nos rumos das empresas do setor. A indústria brasileira, mesmo assim, ainda considera esse processo o mais rápido, eficiente e de fácil consolidação.

A pesquisa, ao sugerir que não existe o processo de globalização tecnológica na indústria brasileira de polímeros, reforça a tese de Perrino e Tipping (1989) que diz: enquanto os mercados se globalizam, o mesmo não ocorre com o desenvolvimento tecnológico.

\section{ReferénCias Biblográficas}

\section{ARCHIBUGI, D.;}

MICHIE, J.

The globalization of technology: a new taxonomy. Cambridge Journal of Economics, v. 19, n. 1, p. 121-140, Feb. 1995.
BARROS, H. M.;

PASTORINI, M. T.;

HEMAIS, C. A.

Trajetória tecnológica da indústria brasileira de polímeros. In: IV CONGRESSO BRASILEIRO DE POLÍMEROS (1997). Anais Eletrônicos... 1997. n. 108. 
BERTIN, G. Y;

WYATT, S.

Multinationals \& industrial property - the control of the world's technology. Harvester : Wheatsheaf Books, 1988.

CASSON, M.

Global research strategy and international competitiveness.

Oxford : Basil Blackwell,1991.

\section{CHESNAIS, F.}

Multinationals enterprises and the international diffusion of technology. In: DOSI, G. et al. (Eds.). Technical change and economic theory. London: Pinter, 1988. cap. 23. p. 497-527.

National systems of innovation, foreign direct investment and the operations of multinationals enterprises. In: LUNDVALL, B. (Ed.). Towards a theory of innovation and interactive learning. London: Pinter, 1992. cap. 13. p. 265-295.

\section{CORONADO, J.}

Plástico dança conforme o ritmo ditado pela China. Plástico Moderno, p. 06-08, jun. 1997.

\section{DESENVOLVIMENTODO MERCA-} DO DE TERMOPLÁSTICOS.

Polímeros : ciência e tecnologia. abr./jun.1995. n. 5, p. 07-12.

DUNNING, J. H.

Multinationals enterprises and the globalization of innovatory capacity. Research Policy, v. 23, p. 67-88, 1994.

FLORIDA, R.

The globalization of R\&D : results of a survey of foreignaffiliated $R \& D$ laboratories in the USA. Research Policy, v. 26, p. 85-103, 1997.

FREEMAN, C.

The "national system of innovation" in historical perspective. Cambridge Journal of Economics, v. 19, n.1, p. 0524, Feb. 1995.

HEMAIS, C. A.

Model of international transfer of technology : a theoretical approach. Technology Management : Strategies \& Applications, v. 3, p. 213-227, 1997.

JACOBSSON, S.;

OSKARSSON, C.;

PHILIPSON, J.

Indicators of technological activities-comparing educational, patent and R\&D statistics in the case of Sweden. Research Policy, v. 25, p. 573-585, 1996.

KUMMERLE, W.

Building effective R\&D capabilities abroad. Harvard Business Review, p. 61-70, Mar./ Apr. 1997. 
MALDONADO, J. M. V.

O Brasil face ao processo de globalização tecnológica : $o$ segmento de novos polímeros em foco. Rio de Janeiro, 1996. Tese (Doutorado) - Universidade Federal do Rio de Janeiro.

PATEL, P.;

PAVITT, K.

Large firms in the production of the world's technology : an important case of non-globalization. In: G R A N S T R A N D , O .; HAKANSON, L.; SJÖLANDER, S.(Eds.). Technology management and international business internationalization of $R \& D$ and technology. London: Pinter, 12992. cap.3. p. 53-74.

PAVITT, K.

Foreword. In: BERTIN, G.Y.; WYATT, S. Multinationals \& industrial property - the control of the world's technology. Harvester : Wheatsheaf Books, 1988. p. XI-XX.

PENROSE, E. T.

The theory of the growth of the firm. Oxford: BasilBlackwell, 1980.

PERRINO, A. C.;

TIPPING, J. W.

Global management of technology. Research
Technology Management, v. 32, n. 3, p. 12-19, May/June 1989.

PERRONE, O. V.

Importância econômica dos polos petroquímicos. Exposição oral, IMA/UFRJ, 1996.

RONSTADT, R. C.

R\&D abroad by U.S. multinationals. In: STOBAUGH, R.; WELLS JR., L.T. (Eds.). Technology crossing borders : the choice, transfer, and management of international technology flows. Boston, MA : Harvard Business Press, 1984. cap. 11. p. 241-264.

ROSA, E. O. R.

Patentes na indústria brasileira de polímeros : um estudo empírico. Rio de Janeiro, 1998. Dissertação (Mestrado) - Universidade Federal do Rio de Janeiro.

TACHINARDI, M. H.

A guerra das patentes. São Paulo: Paz e Terra, 1993.

UTRACKI, L. A.

History of commercial polymer alloys and blends (from a perspective of the patent literature). Polymer Engineering and Science, v. 35, n. 1, p. 0216, 1995. 